\title{
STRATEGI DIREKTIF KEBERLANJUTAN DAYA SAING WISATA LOKAL
}

\author{
Maya Dewi Dyah Maharani ${ }^{1}$, Linda Noviana ${ }^{2}$ \\ Teknik Lingkungan, Universitas Sahid Jakarta \\ Jl. Prof. Dr. Supomo, SH No. 84 Tebet, Jakarta Selatan \\ Email Korespondensi: mayasudarsono@gmail.com
}

\begin{abstract}
ABSTRAK
Tujuan dari kajian ini adalah (a) menganalisa status keberlanjutan Pengembangan Daya Saing Wisata Lokal (Urban Tourism), (b) menganalisa faktor-faktor leverage untuk mendorong Pengembangan Daya Saing Wisata Lokal (Urban Tourism), serta (c) merumuskan Skenario Strategi Direktif Daya Saing Wisata Lokal (Urban Tourism). Metode yang digunakan adalah analisis Multi-Dimensional-Scaling (MDS) untuk menghitung status keberlanjutan Pengembangan Daya Saing Wisata Lokal (Urban Tourism), dan menganalisis faktor leverage untuk mendorong Pengembangan Daya Saing Wisata Lokal (Urban Tourism). Analisis dilanjutkan dengan metode Analitycal Hierarchy Process (AHP) untuk menemukan skenario Strategi Direktif Daya Saing Wisata Lokal (Urban Tourism). Hasil kajian menemukan bahwa status keberlanjutan Daya Saing Wisata Lokal (Urban Tourism) multidimensi sebesar 52.77 (cukup berkelanjutan). Rumusan Strategi Direktif Pengembangan Daya Saing Wisata Lokal (kasus: Urban Tourism Bogor, dan Semarang) adalah Pengembangan Atraksi Wisata Tradisional dengan skor 0.202 .
\end{abstract}

Kata Kunci: Strategi, Daya Saing, Wisata Lokal, MDS, AHP

\begin{abstract}
The purpose of this study is (a) to analyze the sustainability status of the Development of Local Tourism Competitiveness (Urban Tourism), (b) analyze the leverage factors to encourage the Development of Local Tourism Competitiveness (Urban Tourism), and (c) formulate the Scenario of the Directive Power Strategy Local Tourism Competitiveness (Urban Tourism). The method used is a Multi-Dimensional-Scaling (MDS) analysis to calculate the sustainability status of Local Tourism Competitiveness Development (Urban Tourism), and analyze the leverage factor to encourage the Development of Local Tourism Competitiveness (Urban Tourism). The analysis continued with the Analitycal Hierarchy Process (AHP) method to find the scenario of the Local Tourism Competitiveness Directive Strategy (Urban Tourism). The results of the study found that the sustainability status of multidimensional Local Tourism (Urban Tourism) was 52.77 (quite sustainable). Formulation of the Directive Strategy for Developing Local Tourism Competitiveness (case: Bogor Urban Tourism, and Semarang) is the Development of Traditional Tourist Attractions with a score of 0.202.
\end{abstract}

Keywords: Strategy, Competitiveness, Local Tourism, MDS, AHP 


\section{PENDAHULUAN}

Pembangunan Daerah dimaknai dalam empat gatra, yaitu (a) sebagai perubahan yang dinamis, (b) diimplementa sikan secara bertahap, (c) untuk seluruh masyarakat, serta (d) kondisi terakhir harus lebih disukai (preferable). Gatra kondisi terakhir lebih disukai (preferable) dalam keberlanjutan manajemen pembangunan daerah dan manajemen lingkungan, ditunjukkan oleh keberhasilan atau kegagalan yang diukur dalam indikator kinerja utama (IKU) dan indikator kinerja kunci (IKK). Tujuan dari kajian ini adalah menganalisis status keberlanjutan Pengembangan Daya Saing Wisata Lokal (Urban Tourism), (b) menganalisa faktor-faktor leverage untuk mendorong Pengembangan Daya Saing Wisata Lokal (Urban Tourism), serta (c) Merumuskan Skenario Strategi Direktif untuk Daya Saing Wisata Lokal (Urban Tourism). Ukuran keberhasilan atau kegagalan digambarkan dengan Indikator Kinerja Utama (IKU) yang berorientasi pada hasil atau outcome. Hal ini akan bermanfaat dalam Penyusunan Keberlanjutan Rencana Pembangunan Jangka Menengah Daerah (RPJMD) periode 20202024. Manfaat lain adalah membantu Pembuat Kebijakan untuk mengevaluasi proses Keberlanjutan Pembangunan Daerah dan Pengelolaan Lingkungan Daerah.

Tujuan Wisata, selanjutnya disebut sebagai komponen Tujuan Wisata Lokal (Urban Tourism), adalah wilayah geografis yang terletak di satu atau lebih wilayah administratif di mana terdapat Objek Wisata, Fasilitas Umum, Fasilitas, Aksesibilitas, dan Interrelated Masyarakat, serta Kelengkapan Realisasi Wisata (Undang-Undang Nomor: 03, 2017). Komponen Tujuan Wisata harus memiliki Daya Tarik Wisata, tanpa Daya Tarik komponen Tujuan Wisata sulit untuk dikembangkan, karena Daya Tarik Wisata adalah salah satu sumber potensi pariwisata. Selain itu, komponen Objek Wisata dijelaskan sebagai segala sesuatu yang memiliki keunikan, kesederhanaan, serta nilai keragaman kekayaan alam, budaya, dan hasil buatan manusia adalah target atau kunjungan wisata. Komponen Atraksi Wisata adalah segala sesuatu yang merupakan daya tarik bagi orang untuk mengunjungi daerah tertentu. Komponen Objek wisata adalah segala sesuatu yang memiliki daya tarik, keunikan dan nilai tinggi, yang menjadi tujuan Wisatawan datang ke daerah tertentu (Geoffrey Wall, 2015).

Untuk dapat mengukur keberhasilan atau kegagalan tujuan pariwisata di daerah tujuan wisata, telah diperkenalkan istilah komponen Daya Saing Tujuan Wisata yang lebih menjadi fokus dan kepedulian terhadap Pemerintah Pusat, Provinsi, Kabupaten, Peneliti dan Praktisi di bidang Pariwisata. Daya saing tujuan wisata dapat ditafsirkan sebagai kemampuan tujuan wisata untuk mengantarkan Barang dan Jasa yang lebih baik daripada tujuan wisata lainnya dalam pengalaman wisata yang dianggap penting oleh wisatawan (Cristina Maria Santos Estevao, 2018). Berbagai penelitian konseptual dan empiris telah dilakukan, untuk merumuskan ukuran keberhasilan pariwisata, tetapi belum ditampung oleh pemerintah daerah. Keberhasilan perumusan kinerja heihaiden dan daya saing pariwisata lokal penting untuk melihat keberhasilan atau kegagalan tujuan pembangunan pariwisata di suatu daerah. Isu berikutnya, untuk daerah perkotaanspesifik dari strategi daya saing pariwisata lokal (Urban Tourism) skenario dan ukuran keberhasilan yang digambarkan melalui pencapaian indikator kinerja utama dan kunci daya saing wisata lokal (Urban pariwisata) masih belum dilengkapi dengan metode ilmiah (Peraturan Menteri Pendayagunaan Aparatur Negara dan Reformasi Birokrasi nomor 1 2012, nomor 53, 2014; Nomor: 9, 2015; Nomor: 17, 2017). 
Faktor kunci dalam keberhasilan tujuan wisata adalah kemampuan untuk bersaing dengan tujuan wisata lainnya. Tujuan wisata harus menyadari posisi bersaing serta potensi yang telah dibandingkan dengan tujuan wisata lainnya untuk dapat bersaing di pasar pariwisata. Oleh karena itu menilai kemampuan tujuan wisata dan kemudian membandingkan dengan wisata lain untuk menjadi hal penting untuk dilakukan. Penilaian daya saing tujuan wisata, dalam hal ini pariwisata perkotaan di kota Bogor akan membantu kebijakan untuk mengembangkan strategi yang bersaing melalui kajian skenario strategi pengembangan daya saing pariwisata lokal berdasarkan Keunggulan dan kelemahan yang dimiliki oleh tujuan wisata (Ardiansyah Muhammad et. Al. 2018, JongHyeong Kim 2017, Kim, J.H., Ritchie, J., \& McCormick, B. 2012, Omer F. Sari, Saim Ozdemir, \& Ahmet Celebi. 2016, Martin, Lusticky \& Tomas, Kincl. 2012, Mikhazi, Zsuzsanna dan Kovacs, Krisztina Felipne. 2011, Gunn, Clare A. 2002).

\section{METODE PENELITIAN}

Penelitian ini dilaksanakan pada bulan Oktober-2018 Desember tahun lalu, dan dilakukan di Bogor, dan kota Semarang. Teknik pengumpulan data dan informasi yang dikendalikan, iteratif dan umpan balik dilakukan melalui konsultasi dengan para ahli pariwisata yang terdiri dari pemerintah, akademisi dan elemen swasta (Lampiran 1). Metode analisis data yang digunakan adalah: (i). multi dimensi scaling (MDS); (II) analisa leverage; (III). analisis Monte Carlo; dan (IV) Analytical hirarki proses metode.

\section{Multi-Dimensional-Scaling (MDS)}

Untuk menilai status keberlanjutan pengembangan daya saing pariwisata lokal menggunakan metode rap-Tourism telah dimodifikasi dari program Rapfish dengan teknik multi-dimensi scaling (Lili dan Dewi 2015). Dalam teknik MDS elemen atau atribut dari pariwisata lokal untuk diukur dan dapat dipetakan dalam jarak Euclidian dengan rumus berikut:

$$
d_{1,2}=\sqrt{\left(X_{1}-X_{2}\right)^{2}+\left(Y_{1}-Y_{2}\right)^{2}+\left(Z_{1}-Z_{2}\right)^{2}+\ldots} \text { (1) }
$$

\section{Keterangan:}

$\mathrm{d}_{1,2} \quad=$ Jarak Euclidean

$\mathrm{X}, \mathrm{Y}, \mathrm{Z}=$ Atribute

$1,2=$ Unit Observasi

Jarak euclidian antara dua titik (D1,2) maka dalam MDS diproyeksikan menjadi jarak Euclidean dua dimensi (D்1) berdasarkan rumus regresi dalam persamaan berikut:

$\mathrm{D}_{1,2}=\mathrm{a}+\mathrm{b} \mathrm{D}_{1,2}+\mathrm{c}$ 2

Keterangan:

$\mathrm{a}=$ intercept

$\mathrm{b}=$ slope

$\mathrm{c}=$ kesalahan 
Analisis MDS, objek dipetakan dalam satu titik yang berdekatan. Teknik MDS yang digunakan adalah algoritma ALSCAL yang mudah tersedia di hampir setiap perangkat lunak Statistik (SPSS dan SAS). Rrcs pada prinsipnya membuat iterasi proses regresi sedemikian rupa, dalam rangka untuk mendapatkan nilai e terkecil dan mencapai persamaan $(\mathrm{a}=0)$. Iterasi berhenti jika Stress adalah $<0,25$. Untuk atribut sebanyak $\mathrm{m}$, nilai stres dirumuskan dalam persamaan berikut:

$$
\text { stress }=\sqrt{\frac{1}{m} \sum_{k=1}^{m}\left(\frac{\sum_{i} \sum_{j}\left(D_{i j k}^{2}-d_{i j k}^{2}\right)^{2}}{\sum_{i} \sum_{j} d_{i j k}^{2}}\right)}
$$

\section{Tabel 1. Nilai stress}

\begin{tabular}{lll}
\hline No & Nilai Stress & Makna \\
\hline 1 & $>20.00 \%$ & Bad \\
2 & $>(10.00-20.00) \%$ & Enough \\
3 & $>(5.00-10.00) \%$ & Good \\
4 & $(2.50-5.00) \%$ & Very good \\
\hline
\end{tabular}

Sumber: Kavanagh dan Pitcher (2004)

\section{Analisis Leverage.}

Analisis leverage untuk menentukan efek stabilitas jika salah satu atribut dihilangkan saat ordinasi. Hasil analisis leverage menunjukkan persentase di root mean Square (RMS) dari masing-masing atribut. Atribut yang memiliki persentase tertinggi adalah atribut yang paling sensitif untuk keberlanjutan

\section{Analisis Monte Carlo}

Untuk mengevaluasi efek kesalahan pada nilai penahbisan, analisis Monte Carlo digunakan, untuk mengevaluasi efek kesalahan acak dalam proses estimasi, dan untuk mengevaluasi nilai aktual.

\section{HASIL DAN PEMBAHASAN}

\section{Indek Keberlanjutan Dimensi Ekologi}

Dimensi ekologi adalah salah satu dimensi penting dalam status keberlanjutan. Oleh karena itu, harus dipertimbangkan untuk jangka panjang ketika merumuskan strategi arahan pengembangan daya saing lokal. Berdasarkan analisis yang dilakukan, nilai indeks dimensi ekologis sebesar 53,12 persen yang berarti bahwa pengembangan daya saing pariwisata setempat dinilai cukup berkelanjutan untuk dimensi ekologi (gambar 1). 


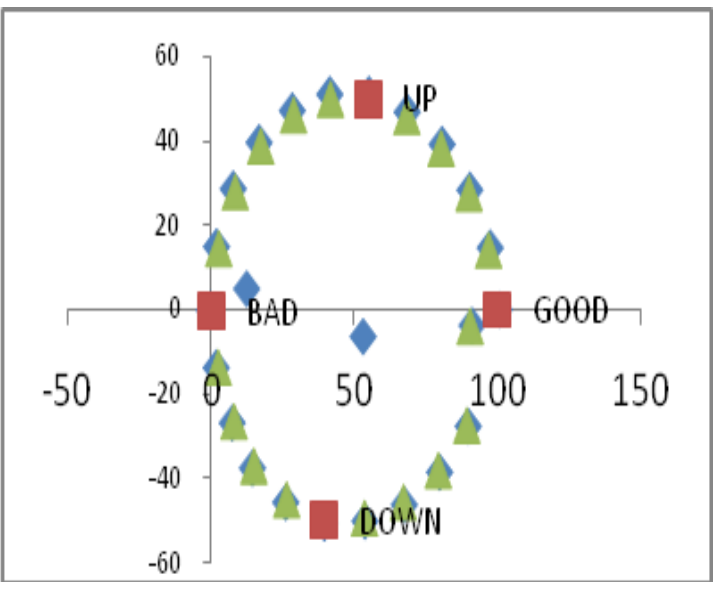

Gambar 1. Status Keberlanjutan Dimensi Ekologi

Terdapat 11 atribut yang diperkirakan mempengaruhi dimensi ekologi. Lokasi tempat wisata yang telah sesuai dengan rencana perencanaan tata ruang daerah dan rancangan layout detail dengan nilai dari akar mean Square (RMS) dari 5,16 dan fungsi pos pengawasan kesehatan dan lalu lintas hewan (epidemi dan pandemi) dengan nilai RMS of 5,08 memiliki pengaruh besar pada indeks keberlanjutan dimensi ekologi. Koefisien penentuan (R2) sebesar 0,950 yang berarti bahwa 11 atribut termasuk memiliki peran yang cukup besar dalam menjelaskan keragaman pengembangan daya saing pariwisata lokal dari dimensi ekologis dibangun. Besarnya nilai S Stress 0,213 $(<0,25)$ berarti keakuratan kebaikan model Fit yang dibangun untuk keberlanjutan dimensi ekologi dapat mewakili model yang baik (Alder et al. 2003). Perbedaan dalam hasil penghitungan MDS dengan hasil analisis Monte Carlo 0,109 $(<1)$, menunjukkan tingkat presisi yang tinggi (Kavanagh dan pitcher 2004).

\section{Indek Keberlanjutan Dimensi Ekonomi}

Hasil analisa nilai indeks dimensi ekonomi 50,19 (cukup berkesinambungan). Ada 9 atribut yang diharapkan mempengaruhi dimensi ekonomi. Empat atribut nilai tertinggi adalah manfaat Layanan Manajemen perjalanan dengan nilai RMS sebesar 5,53; Orientasi unit usaha jasa perjalanan dengan nilai RMS 5,44; Kesediaan tur dan layanan Hotel, Restoran dan katering untuk menerapkan kebersihan dan sanitasi dengan nilai RMS 5,09; Jadwal waktu kunjungan pengaturan dengan nilai RMS 5,28. Koefisien penentuan (R2) sebesar 0,954 yang berarti bahwa sembilan aspek termasuk memiliki peran besar dalam menjelaskan keragaman pengembangan daya saing pariwisata lokal dimensi ekonomi yang mapan. Besarnya nilai stres $S$ adalah $0,218(<0,25)$ yang berarti konfigurasi yang tepat dari kebaikan model Fit yang dibangun untuk keberlanjutan dimensi ekonomi dapat mewakili model yang baik (Alder et al. 2003). Perbedaan dalam nilai MDS yang relatif kecil Monte Carlo adalah 0,057 $(<1)$ mencerminkan tingkat tinggi presisi (Kavanagh dan pitcher 2004). 


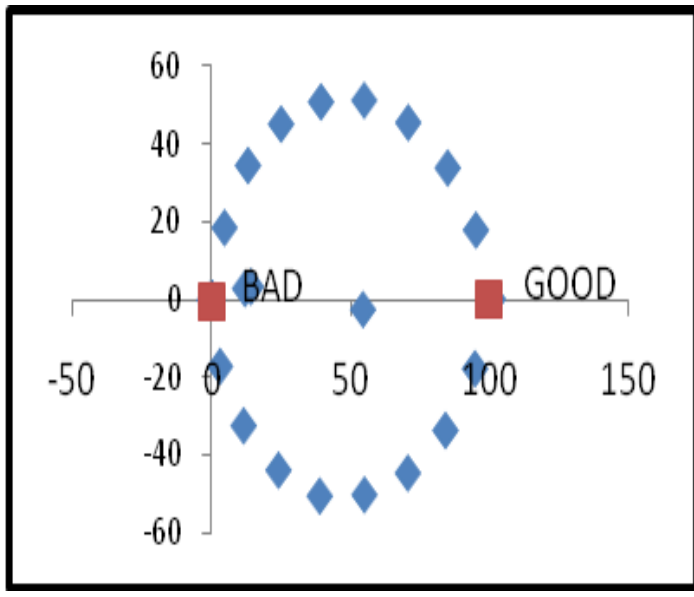

Gambar 2. Indek Keberlanjutan Dimensi Ekonomi

\section{Keberlanjutan Dimensi Sosial}

Hasil dimensi sosial indeks keberlanjutan analisis 54,17 (cukup berkelanjutan). Budaya dan interaksi sosial dengan nilai RMS 6,10 adalah atribut yang memiliki nilai tertinggi dan merupakan faktor kunci yang harus diperhatikan. Atribut budaya dan interaksi sosial merupakan pertimbangan karena berkaitan dengan pengalaman wisatawan dalam berinteraksi dengan komunitas lokal dan budaya di sekitar lokasi wisata. Koefisien penentuan (R2) memiliki nilai 0,958 yang berarti bahwa ketujuh atribut termasuk memiliki peran besar dalam menjelaskan keragaman pengembangan daya saing pariwisata lokal dimensi sosial yang dibangun.

Besarnya nilai stres $S$ adalah $0,212(<0,25)$ yang berarti konfigurasi yang tepat dari kebaikan model Fit yang dibangun untuk keberlanjutan dimensi sosial dapat mewakili model yang baik (Alder et al. 2003). Perbedaan dalam hasil penghitungan MDS dengan hasil analisis Monte Carlo yang relatif kecil adalah 0,132 (<1) yang mencerminkan tingkat presisi yang tinggi (Kavanagh dan pitcher 2004).

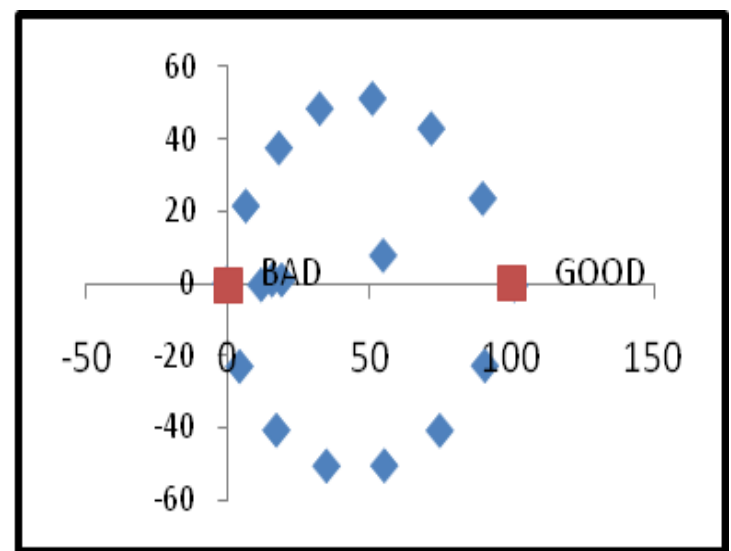

Gambar 3 Keberlanjutan Dimensi Sosial

Validasi dan hasil simulasi MDS dengan Program RAP-Tourism untuk tiga dimensi dapat dilihat pada tabel 2 
Tabel 2. Data hasil nilai $\mathbf{R}^{2}$, nilai stress, analisa MDS dan Monte Carlo

\begin{tabular}{llllll}
\hline Dimensi & $\mathbf{R}^{2}$ & stress & MDS & $\begin{array}{l}\text { Monte } \\
\text { Carlo }\end{array}$ & $\begin{array}{l}\text { selisi } \\
\mathbf{h}\end{array}$ \\
\hline Ekologi & 0,95 & 0,213 & 53,12 & 53,01 & 0,11 \\
Ekonomi & 0 & & & & \\
& 0,95 & 0,218 & 50,19 & 50,13 & 0,06 \\
Sosial & 4 & & & & \\
& 0,95 & 0,212 & 54,30 & 54,17 & 0,13 \\
& 8 & & & & \\
\hline
\end{tabular}

Uji uji pairwise dari penilaian ahli, menghasilkan Skor keberlanjutan tertimbang Multidimensional sebesar 52,77 (cukup berkelanjutan). Penilaian atribut yang dilakukan melalui penelitian menunjukkan bahwa perkembangan daya saing pariwisata daerah cukup berkesinambungan (Tabel 3).

Tabel 3. Nilai indeks keberlanjutan multidimensi

\begin{tabular}{llll}
\hline Dimensi & Bobot Dimensio (\%) & Indek & Hasil pembobotan \\
\hline Ekologil & 0,60 & 53,12 & 31,872 \\
Ekonomi & 0,20 & 50,19 & 10,038 \\
Sosial & 0,20 & 54,30 & 10.860 \\
\hline Amount & 1,00 (inkonsistensi 0,03) & & 52,770 \\
\hline
\end{tabular}

\section{Analytical Hierarchy Process (AHP)}

Analytical hirarki Process (AHP) adalah salah satu metode analisis data untuk proses memilih bidang alternatif yang diperiksa. AHP dikembangkan oleh Dr Thomas L. AHP dikembangkan oleh Dr Thomas L. SAATY dari Wharton School of Business pada tahun 1970 untuk organisir informasi dan pendapat ahli (penghakiman) dalam memilih alternatif yang paling disukai (SAATY 1983). Dengan menggunakan AHP sebuah isu akan diselesaikan dalam kerangka pemikiran terorganisir, sehingga dapat diungkapkan untuk membuat keputusan yang efektif pada masalah ini. Masalah yang kompleks dapat disederhanakan dan mempercepat proses pengambilan keputusan.

Leverage atribut yang ditemukan dibahas melalui survei ahli, dengan wawancara mendalam dan diproses menggunakan metode AHP dengan pilihan ahli perangkat lunak. Tahap ini akan menghasilkan strategi Directive alternatif

Tabel 4. Dimensi dan atributes dari hasil leverage

\begin{tabular}{rr}
\hline Atribute & $\begin{array}{l}\text { Root } \\
\text { Mean } \\
\text { Square }\end{array}$ \\
\hline The willingness of tour and & 5.09 \\
Hotel-Restaurant-Catering & \\
\hline
\end{tabular}




\begin{tabular}{rc}
\hline Atribute & $\begin{array}{c}\text { Root } \\
\text { Mean } \\
\text { Square }\end{array}$ \\
\hline $\begin{array}{r}\text { service managers to implement } \\
\text { hygiene and sanitation }\end{array}$ \\
\hline $\begin{array}{r}\text { Orientation of travel Services } \\
\text { business Unit (local-inter- } \\
\text { national-international) }\end{array}$ \\
Visit Time schedule settings \\
Functioning of health \\
supervision and animal traffic \\
(epidemic and pandemic) \\
Location of the tourist spots that \\
are already in accordance with \\
the plan of Regional Spatial \\
Planning and plan details of \\
spatial \\
\end{tabular}

Ketujuh atribut leverage kemudian dilakukan dengan penilaian tingkat pengaruh antara atribut, baik secara langsung maupun tidak langsung. Hal ini dilakukan mengingat ada hubungan antara masing-masing atribut dalam. Hubungan antara atribut ini dapat menjadi pengaruh atau ketergantungan antara atribut. Hasil analisis AHP diperoleh seperti pada Tabel 5.

Tabel 5. Kriteria Utama dan alternatif strategi

\begin{tabular}{rrrr}
\hline Kriteria Utama & nilai & $\begin{array}{c}\text { Alternatif } \\
\text { strategi }\end{array}$ & Nilai \\
\hline $\begin{array}{r}\text { Location of the } \\
\text { tourist spots that }\end{array}$ & 0,31 & $\begin{array}{r}\text { Tourism } \\
\text { Refresh }\end{array}$ & 0,132 \\
are already in & ment & \\
accordance with & Develop \\
the plan of & ment & \\
Regional Spatial & & \\
Planning and & & \\
\hline
\end{tabular}




\begin{tabular}{|c|c|c|c|}
\hline Kriteria Utama & nilai & $\begin{array}{l}\text { Alternatif } \\
\text { strategi }\end{array}$ & Nilai \\
\hline \multicolumn{4}{|l|}{$\begin{array}{r}\text { plan details of } \\
\text { spatial }\end{array}$} \\
\hline $\begin{array}{r}\text { Functioning of } \\
\text { health } \\
\text { supervision and } \\
\text { animal traffic } \\
\text { (epidemic and } \\
\text { pandemic) }\end{array}$ & 0,20 & $\begin{array}{r}\text { Knowled } \\
\text { ge } \\
\text { develop } \\
\text { ment of } \\
\text { tourists }\end{array}$ & 0,165 \\
\hline $\begin{array}{r}\text { The willingness } \\
\text { of tour and } \\
\text { Hotel- } \\
\text { Restaurant- } \\
\text { Catering service } \\
\text { managers to } \\
\text { implement } \\
\text { hygiene and } \\
\text { sanitation }\end{array}$ & 0,07 & $\begin{array}{l}\text { Develop } \\
\text { ment of } \\
\text { Amenita } \\
\mathrm{s} \text { in the } \\
\text { area of } \\
\text { tourist } \\
\text { destinati } \\
\text { ons }\end{array}$ & 0,163 \\
\hline $\begin{array}{r}\text { Orientation of } \\
\text { travel Services } \\
\text { business Unit } \\
\text { (local-inter- } \\
\text { national- } \\
\text { international) }\end{array}$ & 0,12 & $\begin{array}{l}\text { Road } \\
\text { infrastru } \\
\text { cture } \\
\text { develop } \\
\text { ment } \\
\text { around } \\
\text { tourist } \\
\text { destinati } \\
\text { ons }\end{array}$ & 0,192 \\
\hline $\begin{array}{r}\text { the benefits of } \\
\text { travel } \\
\text { management } \\
\text { services }\end{array}$ & 0,11 & $\begin{array}{l}\text { The } \\
\text { tradition } \\
\text { al } \\
\text { tourist } \\
\text { attractio } \\
\text { n } \\
\text { develop } \\
\text { ment }\end{array}$ & 0,202 \\
\hline $\begin{array}{r}\text { Culture and } \\
\text { social } \\
\text { interaction }\end{array}$ & 0,04 & $\begin{array}{l}\text { Tourism } \\
\text { promotio } \\
\text { n } \\
\text { Develop } \\
\text { ment }\end{array}$ & 0,157 \\
\hline
\end{tabular}




\begin{tabular}{rlll}
\hline Kriteria Utama & nilai & $\begin{array}{l}\text { Alternatif } \\
\text { strategi }\end{array}$ & Nilai \\
\hline $\begin{array}{r}\text { Visit Time } \\
\text { schedule }\end{array}$ & 0,02 & & \\
settings & & & \\
\hline
\end{tabular}

Berdasarkan hasil analisis AHP diperoleh bahwa strategi alternatif yang paling layak adalah pengembangan daya tarik wisata tradisional (0202). Strategi alternatif prioritas kedua adalah pembangunan infrastruktur jalan di sekitar lokasi wisata dengan nilai $(0,192)$. Dengan analisis Logis frame kerja, memperoleh indikator kinerja utama dan kunci untuk pengembangan atraksi tradisional strategi pariwisata adalah indeks kepuasan wisatawan. Sementara indikator kinerja utama serta kunci strategi pengembangan infrastruktur jalan di sekitar tujuan wisata adalah indeks loyalitas wisatawan

\section{KESIMPULAN}

Strategi direktif untuk pengembangan daya saing pariwisata lokal (kasus: Urban Tourism Bogor, dan Semarang) adalah sebuah pengembangan atraksi wisata tradisional. Atraksi tradisional dapat bersumber dari arsip statis yang didasarkan pada sejarah skenario strategi direktif dilakukan melalui: (a) ukuran keberhasilan strategi atau indikator kinerja utama serta kunci, yaitu kepuasan Indeks pengunjung, (b) tujuh atribut leverage. Ketujuh atribut leverage meliputi: (1) lokasi tempat wisata yang sudah sesuai dengan rencana perencanaan tata ruang daerah dan rencana rincian spasial; (2) fungsi pengawasan kesehatan dan lalu lintas hewan (epidemi dan pandemi); (3) kesediaan para manajer Layanan Tour dan Hotel-Restaurant-Catering untuk menerapkan hygiene dan sanitasi; (4) orientasi unit usaha jasa perjalanan (local-Inter-National-International); (5) budaya dan interaksi sosial; (6) manfaat Layanan Manajemen perjalanan, dan (7) pengaturan jadwal kunjungan waktu

\section{DAFTAR PUSTAKA}

Alder, J., Pitcher, T. J., Preikshot, D., Kaschner, K., \& Ferriss, B. (2000). How good is good?: A rapid appraisal technique for evaluation of the sustainability status of fisheries of the North Atlantic. Fish. Cent. Res. Rep., 8(2), 136-182.

Budi, S. P. (2015). Model Struktural Pengembangan Daya Saing Destinasi Wisata Studi Kasus Kota Jakarta.

Dahliani, L., \& Maharani, M. D. D. (2018, July). Palm Oil Sustainable Management Using MDS Model from Social Dimension. In 2018 3rd International Conference on Education, Sports, Arts and Management Engineering (ICESAME 2018). Atlantis Press.

Fortes, V. M. M., Ratten, V., Barcellos, P. F. P., \& Estevão, C. (2018). The study of competitiveness of tourism in Cape Verde: the case of clusters of St. Anthony/São 
Vicente and Sal/Boavista. International Journal of Business and Globalisation, 20(3), 292-315.

Gunn, C. A., \& Var, T. (2002). Tourism planning: Basics, concepts, cases. Psychology Press.

Kavanagh, P., \& Pitcher, T. J. (2004). Implementing Microsoft Excel software for Rapfish: a technique for the rapid appraisal of fisheries status.

Kim, J. H. (2018). The impact of memorable tourism experiences on loyalty behaviors: The mediating effects of destination image and satisfaction. Journal of Travel Research, 57(7), 856-870.

Kim, J. H., Ritchie, J. R., \& Brent, M. Bryan (2012).“. Development of a Scale to Measure Memorable Tourism Experiences.” Journal of Travel Research, 51(1), 12-25.

Martin, L., \& Tomáš, K. (2012). Tourism destination benchmarking: Evaluation and selection of the benchmarking partners. Journal of Competitiveness, 4(1), 99-116.

Muhammad, A., Aisjah, S., \& Rofiq, A. (2018). Penilaian Memorable Tourism Experience sebagai Faktor Penentu Daya Saing Destinasi Wisata dengan Menggunakan Pendekatan Rapid Appraisal (Rap). MIX: Jurnal Ilmiah Manajemen, 8(2), 272-291.

Peraturan Menteri Pendayagunaan Aparatur Negara dan Reformasi Birokrasi Republik Indonesia Nomor:25 tahun 2012 tentang; Petunjuk Pelaksanaan Evaluasi Akuntabilitas Kinerja Instansi Pemerintah

Peraturan Menteri Pariwisata Republik Indonesia Nomor 3 Tahun 2017 tentang Pelaksanaan Pelayanan Terpadu Satu Pintu Bidang Pariwisata di Badan Koordinasi Penanaman Modal

Peraturan Menteri Pendayagunaan aparatur Negara dan Reformasi Birokrasi Republik Indonesia Nomor 53 Tahun 2014 tentang Petunjuk Teknis Perjanjian Kinerja, Pelaporan Kinerja, Dan Tata cara Reviu Atas Laporan Kinerja Instansi Pemerintah

Peraturan Menteri Pendayagunaan aparatur Negara dan Reformasi Birokrasi Republik Indonesia Nomor 1 Tahun 2015 tentang Pedoman Evaluasi Kinerja Penyelenggara Pelayanan Publik

Peraturan Menteri Pendayagunaan aparatur Negara dan Reformasi Birokrasi Republik Indonesia Nomor 14 Tahun 2017 tentang Pedoman Penyusunan Survei Kepuasan Masyarakat Unit Penyelenggara Pelayanan Publik

Saaty, T. L. (1980). The analytic Hierarchy Process. McGrawHill international. New York. 
Saaty, T. L. (2000). Fundamentals of decision making and priority theory with the analytic hierarchy process (Vol. 6). RWS publications.

Sari, O. F., Ozdemir, S., \& Celebi, A. (2016, May). Utilization and Management of Poultry Slaughterhouses Wadte with new Methods. In Eurasia 2016 Waste Management Symposium.

Wall, G. (2017). Ethnic and Minority Cultures as Tourist Attractions. Journal of Tourism Futures. 